\title{
A hierarchical approach to defining marine heatwaves
}

\author{
Alistair J. Hobday ${ }^{1}$ \\ Lisa V. Alexander ${ }^{2,3}$ \\ Sarah E. Perkins ${ }^{2,3}$ \\ Dan A. Smale ${ }^{4,5}$ \\ Sandra C. Straub ${ }^{5}$ \\ Eric C. J. Oliver ${ }^{2,6}$ \\ Jessica Benthuysen ${ }^{7}$ \\ Michael T. Burrows ${ }^{8}$ \\ Markus G. Donat ${ }^{2,3}$ \\ Ming Feng ${ }^{9}$ \\ Neil J. Holbrook ${ }^{2,6}$ \\ Pippa J. Moore ${ }^{10}$ \\ Hillary A. Scannell ${ }^{11,12}$ \\ Alex Sen Gupta ${ }^{3}$ \\ Thomas Wernberg ${ }^{5}$
}

1. CSIRO Oceans and Atmosphere, Hobart, Tasmania, 7000, Australia

2. ARC Centre of Excellence for Climate System Science, The University of New South Wales, Sydney, Australia

3. Climate Change Research Centre, The University of New South Wales, Sydney, Australia

4. Marine Biological Association of the United Kingdom, The Laboratory, Citadel Hill, Plymouth PL1 2PB, UK

5. UWA Oceans Institute and School of Plant Biology, The University of Western Australia, Crawley 6009 Western Australia, Australia

6. Institute for Marine and Antarctic Studies, University of Tasmania, Hobart, Australia

7. Australian Institute of Marine Science, Townsville, Queensland, Australia

8. Department of Ecology, Scottish Association for Marine Science, Scottish Marine Institute, Oban, Argyll, PA37 1QA, Scotland, UK.

9. CSIRO Oceans and Atmosphere, Perth, Western Australia, Australia

10. Institute of Biological, Environmental and Rural Sciences, Aberystwyth University, Aberystwyth SY23 3DA, UK

11. School of Oceanography, University of Washington, Seattle, WA, USA

12. NOAA/Pacific Marine Environmental Laboratory, Seattle, WA, USA

Version: December 30, 2015

Progress in Oceanography 


\begin{tabular}{|c|c|c|}
\hline & 1 & Abstract \\
\hline 2 & 2 & \\
\hline $\begin{array}{l}3 \\
4\end{array}$ & 3 & Marine heatwaves (MHWs) have been observed around the world and are expected to \\
\hline $\begin{array}{l}5 \\
6\end{array}$ & 4 & increase in intensity and frequency under anthropogenic climate change. A variety of impacts \\
\hline 7 & 5 & have been associated with these anomalous events, including shifts in species ranges, local \\
\hline $\begin{array}{l}0 \\
9\end{array}$ & 6 & extinctions and economic impacts on seafood industries through declines in important fishery \\
\hline 10 & & \\
\hline 1 & 7 & species and impacts on aquaculture. Extreme temperatures are increasingly seen as important \\
\hline 12 & 8 & influences on biological systems, yet a consistent definition of MHWs does not exist. A clear \\
\hline $\begin{array}{l}14 \\
15\end{array}$ & 9 & definition will facilitate retrospective comparisons between MHWs, enabling the synthesis \\
\hline $\begin{array}{l}16 \\
17\end{array}$ & 10 & and a mechanistic understanding of the role of MHWs in marine ecosystems. Building on \\
\hline $\begin{array}{l}18 \\
19\end{array}$ & 11 & research into atmospheric heatwaves, we propose both a general and specific definition for \\
\hline 20 & 12 & MHWs, based on a hierarchy of metrics that allow for different data sets to be used in \\
\hline 22 & 13 & identifying MHWs. We generally define a MHW as a prolonged discrete anomalously warm \\
\hline $\begin{array}{l}23 \\
24\end{array}$ & 14 & water event that can be described by its duration, intensity, rate of evolution, and spatial \\
\hline $\begin{array}{l}25 \\
26\end{array}$ & 15 & extent. Specifically, we consider an anomalously warm event to be a MHW if it lasts for five \\
\hline $\begin{array}{l}27 \\
28\end{array}$ & 16 & or more days, with temperatures warmer than the $90^{\text {th }}$ percentile based on a 30 -year historical \\
\hline $\begin{array}{l}29 \\
30\end{array}$ & 17 & baseline period. This structure provides flexibility with regard to the description of MHWs \\
\hline 31 & 18 & and transparency in communicating MHWs to a general audience. The use of these metrics is \\
\hline $\begin{array}{l}32 \\
33\end{array}$ & 19 & illustrated for three $21^{\text {st }}$ century MHWs; the northern Mediterranean event in 2003 , the \\
\hline 34 & 20 & Western Australia 'Ningaloo Niño' in 2011, and the northwest Atlantic event in 2012. We \\
\hline $\begin{array}{l}36 \\
37\end{array}$ & 21 & recommend a specific quantitative definition for MHWs to facilitate global comparisons and \\
\hline $\begin{array}{l}38 \\
39\end{array}$ & 22 & to advance our understanding of these phenomena. \\
\hline & 23 & \\
\hline
\end{tabular}

24 Keywords: extreme events; sea surface temperature; anomalous events; temperature 25 anomaly; heatwaves 


\section{Introduction - Marine heatwaves and their ecological impact}

Ecosystems around the world have responded to anthropogenic climate change, with major implications for ecological goods and services (Rosenzweig et al. 2008). Links between a changing climate, shifts in species distributions, and the structure of communities and ecosystems have been documented convincingly for many taxa across many regions (Parmesan and Yohe 2003; Rosenzweig et al. 2008; Poloczanska et al. 2013). Concurrent with these observations, predictions of how species distribution and biodiversity will respond to continued climate change have been developed (e.g. Cheung et al. 2009; Engler et al. 2011; Sen Gupta et al. 2015). However, in conjunction with a distinct long-term warming signal (an increase in mean temperature at a location), the frequency and intensity of extreme temperature events are also increasing (Perkins et al. 2012) as a consequence of anthropogenic climate change (IPCC 2012; Coumou and Ramstorf 2012). It is clear that discrete climatic events can drive step-wise changes in species distributions and, ultimately, ecosystem structure and functioning (Wernberg et al. 2013). Storms, droughts, floods and heatwaves - prolonged period where temperatures are substantially hotter than normal - can have catastrophic effects on terrestrial ecosystems (Jentsch et al. 2007; Smith 2011), with significant socio-economic ramifications. As such, understanding and predicting biological responses to short-term extreme events, rather than long-term change, is becoming increasingly important, although event-based research still lags behind trend-based work (Jentsch et al. 2007).

Extreme climatic events are important in determining ecosystem structure (Jentsch et al. 2007), however, the majority of our current understanding stems from the study of terrestrial ecosystems. Investigation of marine ecosystems is important, as they play a central role culturally, socially and economically in the lives of most people (Richardson and Poloczanska 2008; Bennett et al. 2015). Marine ecosystems, like their terrestrial counterparts, are strongly influenced by extreme climatic events, including heatwaves (Garrabou et al. 2009; Wernberg et al. 2013), cold snaps (Firth et al. 2011), storms (De'ath et al. 2012) and floods (Gillanders and Kingsford 2002), which are driven by complex physical processes interconnected in the climate system and interacting across a hierarchy of spatial and temporal scales (Trenberth 2012; Feng et al. 2014). 
Marine heatwaves (MHWs), which can be caused by a combination of atmospheric and oceanographic processes, have a strong influence on marine ecosystem structure and function. For example, in the boreal summer of 2003 an atmospheric heatwave over northwestern Europe led to enhanced rates of air-sea heat flux into the northern Mediterranean Sea, which in combination with weak winds led to regional-scale thermal stratification and warming anomalies of $2-3^{\circ} \mathrm{C}$ in surface waters (Garrabou et al. 2009). This MHW had profound ecological impacts that included widespread mortality of benthic invertebrates (Garrabou et al. 2009) and loss of seagrass meadows (Marba and Duarte 2010). More recently, during the austral summer of 2011, a MHW off Western Australia (a so-called 'Ningaloo Niño') was largely driven by atmospheric and oceanographic processes associated with the strong 2010/11 La Niña, which led to anomalous advection of warm tropical waters poleward into temperate regions (Feng et al. 2013; Benthuysen et al. 2014). This Western Australia MHW caused major shifts in benthic ecosystem structure and functioning in a tropical-temperate transition zone, through widespread mortality of cool-water habitat forming species (Wernberg et al. 2013; Smale and Wernberg 2013), and impacted a valuable fishery (Caputi et al. 2015). During a $2012 \mathrm{MHW}$ in the northwest Atlantic, rapid shifts in geographical distributions and phenology were observed for several marine species, including those targeted by regional fisheries (Mills et al. 2013). These ecological responses led to altered fishing practices (longfin squid) and harvest patterns (lobsters), with significant political and economic ramifications (Mills et al. 2013).

It is clear that MHWs, which may increase in frequency and magnitude as a result of anthropogenic climate change (IPCC 2012), are important events that can cause rapid changes in biodiversity patterns and ecosystem structure and functioning. Apart from the physical drivers of short-term temperature variability and extremes, there is a pressing need to examine the characteristics of MHWs, and their biological impacts, within a coherent and comparable framework.

\subsection{Defining extreme temperatures in marine systems}

Previous ecological studies have used metrics to assess extreme thermal stress in the marine environment (Table 1). For example, Sorte et al. (2010) adopted the definition of Meehl and Tebaldi (2004) in which marine heatwaves were defined as a period of at least three to five days during which mean or maximum temperature anomalies were at least $3-5^{\circ} \mathrm{C}$ above normal, while Selig et al. (2010) used thermal stress anomalies (TSAs - see Table 1). 
94 Recently, Marba et al. (2015) used SST percentile thresholds for a Mediterranean-focused meta-analysis of MHW impacts, however MHWs are also often described using vague definitions (e.g. statements such as "warmer than average") and most temperature anomalies are generated from monthly datasets, thus smoothing out shorter but generally more intense events. The majority of marine extreme climate event metrics have been developed to monitor and predict coral bleaching, which is the most advanced field of thermal stressrelated marine ecology (Donner et al. 2005; Spillman and Alves 2009). Such metrics generally include the effect of extreme event duration and magnitude of temperature anomalies. Beyond coral reef research there is limited consistency regarding how MHW metrics are applied or how useful they are in ecological applications.

\subsection{Parallels with atmospheric heatwave definitions}

Global initiatives over the last decade have sought to define standard metrics for atmospheric heatwaves and extreme temperatures, primarily under the auspices of the Expert Team on Climate Change Detection and Indices (ETCCDI ${ }^{1}$; Zhang et al. 2011), to allow comparative analyses across regions. The general definition of atmospheric heatwaves is a prolonged period where temperatures are substantially hotter than normal (Perkins and Alexander 2013). Observations of atmospheric extreme events have had considerably more attention over the last decade compared with marine events (e.g. Meehl and Tebaldi 2004; Fischer and Shär 2010; Schoetter et al. 2014), but the absence of a pre-defined framework has seen atmospheric events defined by a plethora of metrics, most of which are unique to a particular purpose or study. The existing metrics are generally simplistic, accounting for only anomaly, magnitude, duration or frequency (Frich et al. 2002; Alexander et al. 2006; Perkins 2011). A few studies, however, have attempted to develop more complex metrics that take into account multiple factors (Della-Marta et al. 2007; Vautard et al. 2013; Russo et al. 2014). In parallel to the climate research community, impact-focused research groups (such as the health sector) have defined an additional suite of heatwave metrics. While these indices also measure the severity of heatwaves, they are configured to relate to thresholds that are specific to a particular application (e.g. metrics for human health purposes: Fanger 1970; Steadman 1984; Mayer and Hoppe 1987). Such metrics often require more than just basic temperature data, making it difficult to derive most impact metrics from regional climatological data. Moreover, the specific nature of each metric to a particular impact reduces its applicability to

\footnotetext{
${ }^{1}$ A joint initiative of the World Meteorological Organisation Commission for Climatology/World Climate Research Programme/ and the Joint WMO-IOC Technical Commission for Oceanography and Marine Meteorology (JCOMM).
} 
another sector, even with similar purposes (Perkins and Alexander 2013). This wide range of metrics within and across these communities also means that different data are required to apply different atmospheric heatwave definitions, which inhibits consistent measurements both spatially and temporally. The lack of consistency in data availability and atmospheric heatwave calculations has made a general assessment of the drivers of these events and their impacts extremely challenging. These limitations have resulted in an assessment for observed trends in atmospheric heatwaves of only medium confidence in the IPCC Special Report on Extremes (IPCC 2012) and the IPCC Fifth Assessment Report (IPCC 2013).

In an attempt to overcome these issues, Perkins and Alexander (2013) presented a working framework to define atmospheric heatwaves and address the issues of inconsistency and assigning confidence. The framework considers what metrics can be derived with statistical rigor from meteorological data, and what characteristics are important for a range of impacts sectors. Based on these criteria, Perkins and Alexander (2013) define an atmospheric heatwave when at least three consecutive days exceed a calendar day threshold defined as the $90^{\text {th }}$ percentile value for temperature. Using a 'day-specific' threshold allows for the detection and measurement of events at all times of the year (i.e. a heatwave can occur in winter with a lower absolute value than might occur in summer), and a percentile-based threshold allows for the measurement of heatwaves across locations that differ in variability. An event is characterized in terms of its duration and intensity, and summary statistics such as the number of discrete events, sum of heatwave days and peak intensity can be calculated for a season or period of interest. The success of the framework is evident in understanding changes in global observed atmospheric heatwaves (Perkins et al. 2012) and future projections from numerical climate models (Cowan et al. 2014). It also supported a finding of high confidence in observed increasing trends in heatwave frequency in Europe, Asia and Australia (IPCC 2013).

While the framework constructed by Perkins and Alexander (2013) has achieved a consistent approach to characterising atmospheric heatwaves, the study of atmospheric heatwaves would have likely been more successful if common definitions had been derived earlier in the study of atmospheric heatwaves. This success would have been further heightened by incorporating levels of metric flexibility and ease of communication. Therefore, there is great potential for the marine community to apply the lessons learned from the atmospheric community in the definition of MHWs. 


\section{A hierarchical definition of marine heatwaves}

From the lessons learned in atmospheric studies, and following Perkins and Alexander (2013), we propose a definition for MHWs that can be used for comparative studies with regional and biological applications. Minor differences to the atmospheric definition (minimum duration and minimum time between events) were implemented because of the naturally longer time scales of ocean variability with regard to atmospheric variability, as explained below. Qualitatively, we propose the definition of a MHW as a discrete prolonged anomalously warm water event in a particular location. From examples such as the 2003 MHW in the northern Mediterranean Sea (Garrabou et al. 2009), the 2011 Ningaloo Niño in Western Australia (Feng et al. 2013) and the 2012 MHW in the northwest Atlantic (Mills et al. 2013; Chen et al. 2014), it is clear that the atmosphere, land surface and ocean all may have important driving roles in how and where these prolonged heat events play out. However the relative importance of these drivers varies amongst events. Therefore, the qualitative definition does not assume any particular heatwave driver nor does it assume that the MHW has any specific impact. However, it does provide a flexible definition that can be specifically targeted towards end-user applications such as coral reef monitoring or fisheries management. In these situations, identification and quantification of heatwave events provides an opportunity to understand and manage impacts, such as when the 2011 Ningaloo Niño decimated commercially important crustacean and mollusc stocks in Western Australia (Pearce et al. 2011; Hodgkinson et al. 2014).

The qualitative definition of a MHW applies to ocean regions (including subsurface waters, estuarine, or enclosed seas such as the Mediterranean Sea or Baltic Sea), but may have limited applications in intertidal zones, where ecological responses to high sea temperatures are mediated by air temperature, precipitation and atmospheric conditions (Helmuth et al. 2006). Under this definition, a MHW can be caused by a combination of atmospheric forcing (e.g. heating) and oceanic conditions (e.g. faster advection or advection of unusually warm water). The MHW should be defined relative to a baseline period (climatology) and a particular time of the year from which the intensity, duration and spatial extent of the MHW could be defined. This also means that a MHW is not just limited to the warmer months, since for some biological applications the consideration of heatwaves in colder months is essential. For example, the reproductive cycle of several seaweed species involves reproduction in colder seasons, and during these seasons the propagules and early post- 
settlement stages are in general more susceptible to thermal stress than adults (Santelices 1990; Lotze et al. 2001). For the fucoid Scytothalia dorycarpa, Andrews et al. (2014) showed that post-settlement juvenile survivorship strongly depended on temperature, with highest survivorship in the coldest treatment, and elevated or complete mortality more likely under elevated temperature. In this case, a MHW in a cold season could lead to suppressed or failed recruitment of habitat-forming seaweeds.

While this qualitative definition provides flexibility in the way in which a MHW can be defined across multiple end users for their particular application, it does not allow for empirical comparisons of the characteristics of MHWs across different events in space and time. For intercomparisons, the general qualitative definition of 'anomalously warm', 'discrete', and 'prolonged' can be quantified:

- 'anomalously warm': A MHW must be defined relative to a baseline climatology (see recommendation section). Based on other studies of ocean drivers (e.g. El Niño-Southern Oscillation), which have long time scales of variability, a period of 30 years $^{2}$ is recommended to define a baseline temperature climatology, wherever possible. This is almost the full period of recorded satellite sea surface temperature observations. The climatology will be defined relative to the time of year, using all data within an 11-day window centred on the time of year from which the climatological mean and threshold are calculated. Limitations, in terms of length, quality, consistency, resolution and availability may restrict this method for some applications. For studies using remotely sensed data, where availability begins in the 1980s and 1990s for sea surface temperature and sea surface height, respectively, the climatological period might have to be shorter, and users should explicitly define their period accordingly. A MHW should be defined relative to a high percentile threshold (e.g. 90\%). A percentile threshold is recommended rather than an absolute value above the climatological value as the magnitude of variability across a range of timescales varies considerably by region. An absolute threshold (e.g. $2^{\circ} \mathrm{C}$ anomaly) would only be relevant in terms of impacts in some regions but not in others (e.g. due to species acclimation). Moreover, by using a percentile rather than standard deviation definition no assumption is made regarding the underlying distribution of anomalies. Users should also be cognisant of biases that might be

\footnotetext{
${ }^{2}$ Guide to Climatological Practices, WMO-No. 100
} 
introduced at the start and end of the base period when calculating threshold exceedances, and in such cases a bootstrapping procedure such as that defined by Zhang et al. (2005) might be employed to calculate percentiles from subsets of the data when a long time series is available.

- 'prolonged': In the marine environment, the definition should be relevant to ecological processes and thresholds (based on evidence of impact), but for each process this threshold may be different. Our general recommendation is that the MHW needs to persist for at least five days. A sensitivity analysis was performed using high-resolution $\left(1 / 4^{\circ}\right)$, global, daily SSTs from the Advanced Very High Resolution Radiometer (AVHRR) satellite data (NOAA OI SST V2; Reynolds et al. 2007) and it was found that for durations shorter than five days there were many more MHWs in the tropical regions than elsewhere, while for durations longer than five days there were often many regions with fewer than one MHW per year, on average. Therefore, we recommend five days as a balance to achieve relatively uniform global MHW counts under current climatic conditions.

- 'discrete': A MHW event is discrete with well-defined start and end times. However, in our proposed definition and in common with atmospheric heatwaves, gaps between events of two days or less with subsequent five day or more events will be considered as a continuous event. For example, five anomalously warm days followed by two cool and then six anomalously warm days would be defined as an 13 day MHW event $\left[5_{\text {hot }}, 2_{\text {cool }}, 6_{\text {hot }}\right]$. In contrast, five anomalously warm days, followed by one cool day, and then two more anomalously warm days would be defined as a five day event $\left[5_{\mathrm{hot}}, 1_{\mathrm{cool}}, 2_{\mathrm{hot}}=5 \mathrm{MHW}\right.$ days $]$; as would the converse $\left[2_{\mathrm{hot}}, 1_{\text {cool }}, 5_{\mathrm{hot}}\right]$. A sequence of five anomalously warm days followed by four cool days and then six anomalously warm days $\left[5_{\text {hot }}, 4_{\text {cool }}, 6_{\text {hot }}\right]$ would be defined as two MHW events, one of five days duration, and one of six days duration.

\subsection{Measurement of marine heatwaves}

MHWs can be identified at any point in the ocean based on quantitative refinement of the qualitative definition provided earlier. For intercomparisons, a standard MHW definition, calculated in exactly the same way and using the same metrics and processing methods, is required. We suggest that the previous values be used as a starting point, but could be modified for a particular region or purpose. A set of summary statistics can be derived for each MHW including, for example, its intensity, duration, frequency and spatial extent. We 
propose that a hierarchical set of such metrics be used to uniquely describe MHWs (Figure

1; Table 2). A hierarchy is useful as different temperature datasets, based on their spatial and temporal resolution, have different abilities to provide different metrics. Primary metrics allow for the most general comparison between duration and magnitude (intensity). For example, for a MHW, duration is defined as the period over which the temperature is greater than the seasonally varying threshold value (also defined in Table 2), while cumulative intensity $\left(i_{\text {cum }}\right)$ is the integral of intensity over the duration of the event, and is equivalent to previously used metrics such as DHDs. Secondary metrics distinguish the temporal trend (i.e. the rate of event onset and decline) and spatial extent of the MHW. Tertiary metrics are very specific to the system under investigation, and include preconditioning environmental conditions, although we do not formally define these conditions. This hierarchy allows some flexibility in the reporting of MHWs, particularly for non-scientific audiences. Measures such as duration and intensity are easily understood, while rates of onset and decline and cumulative intensity may require additional explanation. This set of metrics allows different MHW events to be uniquely described and compared (Figure 2). The MHW definition as used in this manuscript has been implemented as a free software package in Python that calculates all the metrics for a provided time series (marineHeatWaves, http://github.com/ecjoliver/marineHeatWaves).

As described earlier, a number of MHWs have been recorded over recent decades but have been mainly described in general terms as abnormally warm or several degrees above the mean. Comparison of these events across marine environments would be possible by calculating one or more common metrics to all past MHWs. This, in turn, would allow a characterisation based on the hierarchical classifications of metrics, placing the events in a historical context. As an example, three better-known MHW regions are compared here to illustrate the use of these metrics (Figure 3). The metrics for each location were derived from NOAA OI SST, using code implemented in Python (available from https://github.com/ecjoliver/marineHeatWaves). Each region has numerous MHW events that meet our criteria based on the duration and intensity of each event. For example, the location examined off Western Australia (Figure 3a) has experienced 59 MHW events (duration of five days or more) between 1982 and 2014, with the longest MHW lasting for 95 days (13 May 1999 - 15 August 1999) with a maximum $\left(i_{\max }\right)$, mean $\left(i_{\text {mean }}\right)$ and cumulative intensity $\left(i_{\text {cum }}\right)$ of $3.60^{\circ} \mathrm{C}, 2.50{ }^{\circ} \mathrm{C}$ and $237^{\circ} \mathrm{C}$ days above the climatological mean, respectively. By way of comparison, the 2011 event was the largest event according to $i_{\max }\left(6.50^{\circ} \mathrm{C}\right)$ and $i_{\text {mean }}$ 
$\left(3.21^{\circ} \mathrm{C}\right)$, and the second largest MHW after the 1999 event according to duration (60 days) and $i_{\text {cum }}\left(192^{\circ} \mathrm{C}\right.$ days $)$.

For the Mediterranean Sea location, a total of 70 events were identified (Figure 3b).

Different MHW events had the longest duration (2014), highest maximum intensity (2008), and highest mean intensity (2003). The 2003 MHW was the largest event based on the $\mathrm{i}_{\text {mean }}$ $\left(4.06^{\circ} \mathrm{C}\right.$; not shown in Figure $3 \mathrm{~b}$ ) and lasted 30 days by our definition ( 2 June -1 July) with an $\mathrm{i}_{\max }$ of $5.02^{\circ} \mathrm{C}$. The most intense event was in $2008\left(\mathrm{i}_{\max }=5.05\right)$ lasting only 9 days $(26$ June to 4 July) with an $i_{\text {mean }}$ of $3.87^{\circ} \mathrm{C}$. The longest event was still ongoing at the time of analysis, with 110 days (13 September - 31 December 2014 - the end of the dataset), with a lower $\mathrm{i}_{\max }\left(3.31^{\circ} \mathrm{C}\right)$ and $\mathrm{i}_{\text {mean }}\left(2.51^{\circ} \mathrm{C}\right)$, but the highest $\mathrm{i}_{\text {cum }}\left(276^{\circ} \mathrm{C}\right.$ days $)$.

For the selected northwest Atlantic location, 67 events were identified (Figure 3c), with the longest MHW of duration 187 days (31 July 2012 - 2 February 2013) with an $i_{\max }$ and $i_{\text {mean }}$ of $4.00^{\circ} \mathrm{C}$ and $2.37^{\circ} \mathrm{C}$ respectively. The $\mathrm{i}_{\text {cum }}$ for this MHW was $443^{\circ} \mathrm{C}$ days, the highest for any at this location. An earlier event, lasting 21 days (4-24 July 2010), had the highest mean intensity $\left(3.05^{\circ} \mathrm{C}\right)$ in the period considered, but a lower maximum intensity $\left(\mathrm{i}_{\max }=4.24^{\circ} \mathrm{C}\right)$ than a 56 day event in 2012 (10 April - 4 June) where the $i_{\max }$ was $4.89^{\circ} \mathrm{C}$. This latter event is the 2012 northwest Atlantic event discussed in the literature (Mills et al. 2013; Chen et al. 2014). The corresponding $\mathrm{i}_{\text {mean }}$ and $\mathrm{i}_{\text {cum }}$ for this 56 day event was $2.59^{\circ} \mathrm{C}$ and $145^{\circ} \mathrm{C}$ days, respectively. Note that the 56 and 187 day events in 2012 are considered distinct, as the temperature dropped below the threshold for at least 3 days ( 5 days) between the two events.

The collective analysis of the three case study regions demonstrates the need for a diversity of metrics to describe different MHW features. As each of the MHWs is defined by a set of metrics (Table 2), approaches such as principal component analysis can be undertaken to characterise and identify types of MHWs. The metrics for each location may also be used to examine how the frequency of events has changed over time by analysing individual events (e.g. Figure 2), or the total number of MHW days in each year. Finally, the spatial extent of MHWs can be calculated from gridded datasets (e.g. NOAA OI SST) with the analysis of temperature time series repeated for each point in a spatial grid in the wider region of interest. The area where the threshold is exceeded is summed for each day to provide a daily MHW area for each day. These metrics could in turn be used to explore the impact of MHWs on regional biology. As evident from published studies outlined above, persistent and intense 
MHWs have led to widespread and notable ecological impacts, analogous to atmospheric heatwaves. With these consistent set of metrics, comparative analyses, including linking ecological impacts to specific MWH characteristics, can be undertaken. While we have included 'preconditioning' as a tertiary metric in our hierarchy (Table 2), we do not expand further here, as these metrics will likely be specific to particular habitats, regions and species via potential local adaptation to extremes (Palumbi et al. 2014). When researchers describe MHWs in the future, consideration of preconditioning, such as a period of warm, but not anomalous, conditions may provide additional insight into ecological or human impacts of the focal MHW. Their inclusion in our hierarchy thus represents a placeholder to be informed by more studies on preconditioning and may be expanded or discarded in the future.

\subsection{Datasets matter in defining heatwaves}

While a consistent framework to measure MHWs is important, end-users need to be aware that different datasets may provide substantially different heatwave information despite the use of the same metrics. This is generally due to the resolution of the data, but can also relate to other issues of quality, consistency and instrumentation. Datasets with a high spatial and temporal resolution have more variability than those aggregating across larger areas or based on (smoother) longer time means (Smale and Wernberg 2009). An example of the variation that arises from using different datasets for MHW identification is given in Figure 4, which shows the development of the Ningaloo Niño in 2011 from the reconstructed monthly and weekly Reynolds SST dataset (Reynolds et al. 2002), a daily satellite product (NOAA OISST product; Reynolds et al. 2007), and an hourly in situ data logger. All datasets have a similar profile of the evolution of summer and the MHW including the rate of onset and decline, the duration of the event (measured in months), and a warm period preceding the main heatwave. However, the variability in SST magnitude clearly differs between the four datasets, and would result in different metrics of heatwave intensity. The reconstructed SST products have the smallest variability, due to the coarse spatial ( $1^{\circ}$ degree grid) and temporal (monthly and weekly) resolution. This is followed by the daily satellite data, which are finer in spatial $\left(0.25^{\circ}\right.$ degree grid) and temporal (daily) resolution. The high temporal resolution provided by the in situ logger data reveals higher temporal SST variability, but a lower peak intensity than the daily satellite dataset, consistent with previous analysis of sub-surface in situ and daily satellite data in this region (Smale and Wernberg 2009). It is clear that weekly variability in the logger data is smoothed at monthly scales, thus decreasing intensity by including non- 
heatwave days and weeks. Lower spatial resolution data results in reduced intensity because neighbouring non-heatwave areas are included in mean values.

Not only can different datasets generate different values for the same metric, certain indices may simply not be appropriate or derivable from some data sources. Table $\mathbf{3}$ gives an indication of when the indices outlined in the framework may or may not be applicable, and the quality they would provide. For example, in situ data (such as the logger data described above) can provide high frequency information for the more accurate calculation of intensity and duration (if measured in days). However, these local data would not provide an estimate of the spatial extent of a MHW. In contrast, gridded products, such as satellite-derived SSTs and reconstructed daily datasets, allow greater spatial inferences. Model data, in the forms of global and regional models, and reanalysis products, if at a daily scale, may be used for the calculation of all MHW metrics (Table 3). However, resolution may be reduced due to the coarseness of spatial grids and, in the case of regional models, the domain they cover. While useful for other purposes, paleo proxies and traditional ecological data can, at best, only provide quantitative information on long-lived MHWs (e.g. Zinke et al. 2014). A number of other considerations listed in Table 3, including record length, temporal resolution, whether the data have been quality-controlled, and spatio/temporal consistency, should help end-users evaluate what metrics can be derived from a particular product. Such considerations and measurement qualities are indicative only and should be applied to a dataset each time it is used for the measurement of MHWs.

Many of the MHW metrics can be calculated from gridded products, such as SST datasets, reconstructed observational data, and model/reanalysis data. These provide generally similar quality metrics (Table 3). We recommend that the highest quality data available should be used when calculating MHWs and where possible compared to in situ data (also of highquality, e.g. Smale and Wernberg 2009) (e.g. Figure 4). While coarser resolution datasets may provide information about larger areas and/or longer time periods, this information may not be particularly relevant for marine managers or policy makers who require accurate local scale information, particularly on magnitude, to assess likely impacts. For other research applications, such as studies of large-scale climate variability, MHW metrics may require further modification based on the resolution of datasets being used. For example, large-scale gridded data products can be used to examine the size-frequency of MHWs and their intrinsic climatic properties by setting lower thresholds to capture enough discrete warming events for 
statistical analysis (Scannell et al. in review). While this approach is applicable for largescale MHW pattern recognition, it does not resolve the frequency of shorter and more intense MHWs that would benefit from high temporal and spatial resolution data.

\section{Monitoring and forecasting marine heatwaves}

The three regional examples provided in section 2 demonstrate that both large and small MHWs are detected in observational data based on our definitions (Figure 3). In order to identify the risk of MHW impacts on biological activity, the thermal thresholds of the performance of different biological traits must also be known, and is the subject of ongoing research. Although impacts on marine environments are still poorly understood, as detailed earlier, extreme temperature events can affect species distributions and alter ecosystem structure. Thus monitoring and forecasting are important and can be advanced by the use of common metrics to understand and minimise potential impacts on ecological and economic (e.g. fisheries) levels. Near real-time monitoring using the hierarchical classification of metrics discussed here and applied to daily SST data would allow warnings to be issued when areas approach or exceed their specific thresholds (Spillman 2011). For example, Coral Reef Watch is based on near real-time monitoring during the warmest months of the year and is used to identify areas where conditions may be approaching those conducive to coral bleaching (http://coralreefwatch.noaa.gov/satellite/index.php). This early warning system can inform management actions (to reduce additional stressors for example) which can be implemented quickly (e.g. Beeden et al. 2012). In similar ways, this tool can be enabling as an aid for fisheries managers to predict the potential impacts of increased temperature on important habitats (Donnelly 2013), fish distributions (Hobday et al. 2011) and altered catch rates, or whether perhaps they might be better placed to switch to different target species expected to prosper under warmer conditions in the prospective areas (Mills et al. 2013) or implement recovery actions when the event has concluded.

Furthermore, monitoring heatwaves can lead to a better understanding of their development, characteristics and impacts. Near real-time monitoring of ocean surface temperatures based on satellite data is possible, while deployment of submerged data loggers close to the coastline and the use of oceanographic arrays for the open sea could provide information about heat penetration depths and durations. Many of these systems are already in place, such that implementing a reporting system triggered by the proposed hierarchical set of metrics 
would allow characterisation of a MHW as it develops and persists, comparison to historical events, and greater insight into potential impacts.

Besides near real-time monitoring, the metrics can be used to estimate the prevalence of future MHWs. These metrics can be useful at different time scales in forecasting for the following days to weeks and for long-term projections. Using them within a forecasting framework would lead to near-term prediction of MHWs. Tools already exist for short-term and seasonal forecasting, for example Australia's Bureau of Meteorology OceanMAPS system predicts daily SSTs with a one-week lead time (www.csiro.au/bluelink/) and their POAMA model predicts monthly SSTs for the upcoming nine months (www.bom.gov.au/climate/poama2.4/poama.shtml). Including MHW metrics in the forecasting based on daily predictions would help to identify areas where MHWs may occur and actions could be implemented weeks ahead of time, including altering fisheries management boundaries (e.g. Hobday et al. 2011) and coral reef monitoring (Beeden et al. 2012).

439 Projections beyond the near-term could identify future MHW risk areas. Identifying risk 440 areas would be a useful tool for Marine Protected Areas (MPAs) and spatial zoning for 441 aquaculture. In planning MPAs, it is important not only to decide which areas are to be 442 protected, but also where protection would be most useful. For example, protecting high 443 diversity coral reef areas with a high probability of catastrophic disturbances in the near 444 future, including MHWs, may be less favourable in comparison with protecting an area with 445 less biodiversity but a low probability for disturbance (Game et al. 2008). The likelihood of 446 an area experiencing extreme climatic events could thus be used to decide which areas should 447 be protected and which are less resilient and prone to strong impacts with low expectations of 448 recovery. In a similar way, decision-making processes in aquaculture zoning could include 449 the projection of likelihood for MHWs.

\section{4. Recommendations and conclusions}

451 This paper has outlined the growing interest in documenting and understanding marine 452 heatwaves. The adverse impacts of these events span a vast range of marine ecosystems. 453 Atmospheric heatwaves have had a large research focus in recent years and a proliferation of 454 heatwave metrics now exist, largely due to an absence of coordinated efforts in marrying the 
tools and needs of physical scientists and impacts researchers. There is an opportunity for the marine community to learn from this experience, and it is on this basis that we recommend a consistent, hierarchical framework in which to measure MHWs. The three-tier framework allows for an over-arching and consistent measurement of heatwaves, while also providing flexibility in specifying additional metrics, if necessary. Regarding the use of the proposed hierarchical definition and associated metrics, we recommend the following:

1. The adoption of consistent terminology, definitions and metrics by a broad range of researchers interested in MHWs. This will facilitate comparisons between different MHW events, across seasons and at regional scales. It will also facilitate the comparison of observed events against those simulated in model projections, which will be very useful in understanding plausible future changes in MHWs.

2. The use of a flexible hierarchical system allowing for further development of descriptive indices, for particular ecosystems or species as needed by individual research goals.

3. The calculation of MHWs from the highest quality data available. Confidence in the robust detection of MHWs (and capacity to compare between events and examine spatiotemporal trends) will only be achieved with the use of high-quality datasets. Temperature data should be quality controlled, collected over adequate timescales (i.e. at least 30 years for deriving climatological baselines) and at the highest possible resolution. For example, the satellite-derived SST dataset allows for robust detection of MHWs but should be complemented with high quality in situ data (e.g. from coastal temperature loggers or oceanographic moorings). Daily climatological threshold time series (e.g. $90^{\text {th }}$ percentile) may need to be smoothed in order to extract a useful climatology from inherently variable data. Sensitivity testing on daily data suggests that a 30-day 'moving window' is appropriate for smoothing climatology from daily data.

4. To be consistent with the atmospheric heatwave literature, we recommend the $90^{\text {th }}$ percentile be used to define a MHW threshold and that at least five continuous days above this threshold be required to define a MHW. While $10 \%$ of days will be above this threshold, it is generally "rare" for (five) consecutive days above their relative $90^{\text {th }}$ percentile to occur. Shorter heat spikes may have ecological impacts in the ocean, but these are distinct features and just as a few hot air days do not make an atmospheric heatwave, a short sequence of hot ocean days ( $<5$ days) do not represent a MHW under our definition. The use of standardised software would ensure consistency in calculating metrics, but the provision of detailed formulae (Table 2) may be an alternative. These 
metrics can, of course, be modified to suit the specific application, but reporting of standardised metrics will greatly facilitate inter-comparison between events, locations and times.

5. Assessments of spatial and temporal variability in the occurrence of MHWs can be combined with analyses of other important aspects of the marine environment, such as biodiversity patterns (Tittensor et al. 2010), human pressures (Halpern et al. 2008), and hotspots of ocean warming (Hobday and Pecl 2014) or the velocity of climate change (Burrows et al. 2011; Sen Gupta et al. 2014). Such an approach can be used to identify regions that may be particularly susceptible to MHWs (i.e. areas subjected to intense human impacts) or regions where ecological impacts may be particularly severe (i.e. hotspots of biodiversity).

Overall, in a rapidly changing climate, the detection, characterisation, impact assessment and prediction of MHWs will become increasingly important. Marine heatwaves are an emerging area of interdisciplinary research with potential for collaborative initiatives in understanding these phenomena. A recent atmospherically driven marine heatwave in the northeast Pacific during the boreal winters of 2013-2015 had significant downstream effects on North American weather, and also disrupted northeast Pacific fisheries and coastal ecosystems (Bond et al. 2015; Hartman, 2015; Whitney 2015). This event, along with the 2003 Mediterranean Sea, 2011 Western Australia and 2012 Northwest Atlantic MHW, provide an opportunity to investigate the drivers and anomalous properties of MHWs under a hierarchical framework. We recommend that the marine scientific community adopts a coherent and consistent approach to this significant undertaking and considers how advances made in the study of atmospheric heatwaves can assist research on MHWs.

\section{Acknowledgments}

This contribution is an outcome from the working group 'Marine Heatwaves - physical drivers and properties' hosted at the UWA Oceans Institute by TW, DAS, NJH and ECJO. The working group received support from a University of Western Australia Research Collaboration Award, a UWA School of Plant Biology synthesis grant, and the ARC Centre of Excellence for Climate System Science (ARCCSS). This work contributes to the World Climate Research Programme (WCRP) Grand Challenge on Extremes. The workshop, and this paper, makes a contribution to the interests and activities of the International Commission on Climate of IAMAS/IUGG. This is recorded as PMEL contribution number 
521 4403. SEP was supported by ARC grant number DE140100952, MGD by ARC grant

1
522 DE150100456, LVA by ARC grant number CE110001028, DS by NERC IRF

523 NE/K008439/1, TW by ARC grant number FT110100174. MTB was supported by NERC

524 grant NE/J024082/1, JB acknowledges support from CE110001028, EO by ARC grant

525 numbers FS110200029 and CE110001028, PJM by Marie Curie CIG PCIG10-GA-2011-

526303685 and NERC grant NE/J024082/1. 


\section{References}

Alexander, L. V., Zhang, X., Peterson, T. C., Caesar, J., Gleason, B., Klein Tank, A. M. G., Haylock, M., Collins, D., Trewin, B., Rahimzadeh, F., Tagipour, A., Kumar Kolli, R., Revadekar, J. V., Griffiths, G., Vincent, L., Stephenson, D. B., Burn, J., Aguilar, E., Brunet, M., Taylor, M., New, M., Zhai, P., Rusticucci, M., Vazquez Aguirre, J. L. (2006). Global observed changes in daily climate extremes of temperature and precipitation. Journal of Geophysical Research-Atmospheres 111: D05109, doi:10.1029/2005JD006290

Andrews, S., Bennett, S., Wernberg, T. (2014): Reproductive seasonality and early life temperature sensitivity reflect vulnerability of a seaweed undergoing range reduction. Marine Ecology Progress Series 495: 119-129.

Beeden, R., Maynard J. A., Marshall, P. A., Heron, S. F., Willis B. L. (2012). A Framework for Responding to Coral Disease Outbreaks that Facilitates Adaptive Management. Environmental Management 49: 1-13.

Bennett, S., Wernberg, T., Connell, S. D., Hobday, A. J., Johnson, C. R., Poloczanska E. S. (2015). The 'Great Southern Reef': Socio-ecological and economic value of Australia's neglected natural wonder. Marine and Freshwater Research. doi:10.1071/MF15232

Benthuysen J., Feng, M., Zhong, L. (2014). Spatial patterns of warming off Western Australia during the 2011 Ningaloo Niño: Quantifying impacts of remote and local forcing. Continental Shelf Research, 91: 232-246.

Berkelmans R., De'ath G., Kininmonth S., Skirving, W. (2004). A comparison of the 1998 and 2002 coral bleaching events on the Great Barrier Reef: spatial correlation, patterns, and predictions. Coral Reefs 23: 74-83.

Bond, N.A., Cronin, M.F., Freeland, H., Mantua, N. (2015), Causes and impacts of the 2014 warm anomaly in the NE Pacific. Geophysical Research Letters 42: doi:10.1002/2015GL063306

Burrows, M. T., Schoeman, D. S., Buckley, L. B., Moore, P. J., Poloczanska, E. S., Brander, K. M., Brown, C. J., Bruno, J. F., Duarte, C. M., Halpern, B. S., Holding, J., Kappel, C. V., Kiessling, W., O'Conner, M. I., Pandolfi, J. M., Parmesan, C., Schwing, F. B., Sydeman, W. J, Richardson, A. J. (2011). The Pace of Shifting Climate in Marine and Terrestrial Ecosystems. Science 334(652): DOI: 10.1126/science.1210288.

Cai, W., Borlace, S., Lengaigne, M., van Rensch, P., Collins, M., Vecchi, G., Timmermann, A., Santoso, A., McPhaden, M. J., Wu, L., England, M. H., Wang, G., Guilyardi, E., 

warming. Nature Climate Change 4:111-116.

Caputi, N., Feng, M., Pearce, A., Benthuysen, J., Denham, A., Hetzel, Y., Matear, R., Jackson, G., Molony, B., Joll, L., Chandrapavan, A. (2015). Management implications of climate change effect on fisheries in Western Australia. FRDC Project 2010/535. Fisheries Research Report No. 260, Department of Fisheries, Western Australia, 180 pp.

Chen, K., Gawarkiewicz, G. G., Lentz, S. J., Bane, J. M. (2014), Diagnosing the warming of the Northeastern U.S. Coastal Ocean in 2012: A linkage between the atmospheric jet stream variability and ocean response, Journal of Geophysical Research 119:1-10: DOI:10.1002/2013JC009393

Cheung, W. W. L., Lam, V. W. Y., Sarmiento, J. L., Kearney, K., Watson, R., Pauly, D. (2009). Projecting global marine biodiversity impacts under climate change scenarios. Fish and Fisheries 10(3): 235-251, DOI: 10.1111/j.1467-2979.2008.00315.x.

Coumou, D., Rahmstorf, S. (2012). A decade of weather extremes. Nature Climate Change, 2: 491-496.

Cowan, T., Purich, A., Perkins, S., Pezza, A., Boschat, G., Sadler, K. (2014). More frequent, longer, and hotter heat waves for Australia in the Twenty-First Century. Journal of Climate, 27(15): 5851-5871

De'ath G., Fabricius K.E., Sweatman H., Puotinen M. (2012). The 27-year decline of coral cover on the Great Barrier Reef and its causes. Proceedings of the National Academy of Sciences, 109: 17995-17999.

Della-Marta, P. M., Haylock, M. R., Luterbacher, J., Wanner, H. (2007), Doubled length of western European summer heat waves since 1880, Journal of Geophysical Research, 112: D15103, doi:10.1029/2007JD008510.

Donnelly, R. J. (2013). Stewardship action plan 2013: Mitigating ecological risk in a changing climate. Pro-Vision Reef Inc., Cairns Australia. Available at www.provisionreed.org.au

Donner, S. D., Skriving, W. J., Little, C. M., Oppenheimer, M., Hoegh-Guldberg, O. (2005). Global assessment of coral bleaching and required rates of adaptation under climate change. Global Change Biology 11: 2551-2265.

Donner, S. D. (2011). An evaluation of the effect of recent temperature variability on the prediction of coral bleaching events. Ecological Applications 21: 1718-1730. 
Eakin, C.M., Morgan, J.A., Heron, S.F., Smith, T.B., Liu, G., Alvarez-Filip, L., Baca, B., Bartels, E., Bastidas, C., Bouchon, C., Brandt, M., Bruckner, A.W., Bunkley-Williams, L., Cameron, A., Causey, B.D., Chiappone, M., Christensen, T.R.L., Crabbe, M.J.C., Day, O., de la Guardia, E., Díaz-Pulido, G., DiResta, D., Gil-Agudelo, D.L., Gilliam, D.S., Ginsburg, R.N., Gore, S., Guzmán, H.M., Hendee, J.C., Hernández-Delgado, E.A., Husain, E., Jeffrey, C.F.G., Jones, R.J., Jordán-Dahlgren, E., Kaufman, L.S., Kline, D.I., Kramer, P.A., Lang, J.C., Lirman, D., Mallela, J., Manfrino, C., Maréchal, J.-P., Marks, K., Mihaly, J., Miller, W.J., Mueller, E.M., Muller, E.M., Orozco Toro, C.A., Oxenford, H.A., Ponce-Taylor, D., Quinn, N., Ritchie, K.B., Rodríguez, S., Ramírez, A.R., Romano, S., Samhouri J.F., Sánchez, J.A., Schmahl, G.P., Shank, B.V., Skirving, W.J., Steiner, S.C.C., Villamizar, E., Walsh, S.M., Walter, C., Weil, E., Williams, E.H., Roberson,, K.W., Yusuf, Y. (2010). Caribbean Corals in Crisis: Record Thermal Stress, Bleaching, and Mortality in 2005. PLoS ONE, 5: e13969.

Engler, R., Randin, C.F., Thuiller, W., Dullinger, S., Zimmermann, N.E., Araujo, M.B., Pearman, P.B., Le Lay, G., Piedallu, C., Albert, C.H., Choler, P., Coldea, G., De Lamo, X., Dirnbock, T., Gegout, J.-C., Gomez-Garcia, D., Grytnes, J.-A., Heegaard, E., Hoistad, F., Nogues-Bravo, D., Normand, S., Puscas, M., Sebastia, M.-T., Stanisci, A., Theurillat, J.-P., Trivedi, M.R., Vittoz, P., Guisan, A. (2011). 21st century climate change threatens mountain flora unequally across Europe. Global Change Biology 17: 2330-2341.

Fanger, P. O., (1970) Thermal comfort. Analysis and applications for environmental engineering. Danish Technical Press, Copenhagen. 244pp.

Feng, M., McPhaden, M.J., Xie, S.-P., Hafner, J. (2013). La Niña forces unprecedented Leeuwin Current warming in 2011. Scientific Reports 3: 1277. DOI:10.1038/srep01277.

Firth, L.B., Knights, A.M., Bell, S.S. (2011). Air temperature and winter mortality: Implications for the persistence of the invasive mussel, Perna viridis in the intertidal zone of the south-eastern United States. Journal of Experimental Marine Biology and Ecology 400: 250-256.

Fischer, E. M., Schar, S. (2010) Consistent geographical patterns of changes in high-impact European heatwaves. Nature Geoscience 3:398-403. DOI: 10.1038/NGEO866.

Frich, P., Alexander, L. V., Della-Marta, P., Gleason, B., Haylock, M., Klein Tank, A. M. G., Peterson, T. (2002). Observed coherent changes in climatic extremes during the second half of the twentieth century. Climate Research 19: 193-212. 
Game, E. T., Watts, M. E., Woolbridge, S., Possingham, H. P. (2008): Planning for persistence in marine reserves: a question of catastrophic importance. Ecological Applications 18(3): 670-680.

Garrabou J., Coma, R., Bensoussan, N., Bally, M., Chevaldonne, P., Cigliano, M., Diaz, D., Harmelin,, J.G., Gambi, M.C., Kersting, D.K., Ledoux, J.B., Lejeusne, C., Linares, C., Marschal, C., Perez, T., Ribes, M., Romano, J.C., Serrano, E., Teixido, N., Torrents, O., Zabala,, M., Zuberer, F., Cerrano, C. (2009). Mass mortality in Northwestern Mediterranean rocky benthic communities: effects of the 2003 heat wave. Global Change Biology 15: 1090-1103.

Gillanders, B.M., Kingsford, M.J. (2002). Impact of changes in flow of freshwater on estuarine and open coastal habitats and the associated organisms. Oceanography and Marine Biology Annual Review, 40: 233-309.

Halpern, B. S., Walbridge, S., Selkoe, K. A., Kappel, C. V., Micheli, F., D'Agrosa, C., Bruno, J. F, Casey, K. S., Ebert, C., Fox, H. E., Fujita, R., Heinemann, D., Lenihan, H. S., Madin, E. M. P., Perry, M. T., Selig, E. R., Spaulding, M., Steneck R. S., Watson, R. (2008). A Global Map of Human Impact on Marine Ecosystems. Science 319: 948-952. Hartmann, D.L. (2015), Pacific sea surface temperature and the winter of 2014. Geophysical $\underline{\text { Research Letters 42: 1894-1902. doi:10.1002/2015GL063083 }}$

Helmuth, B., Mieszkowska, N., Moore, P.J., Hawkins, S.J. (2006). Living on the edge of two changing worlds: Forecasting the responses of intertidal ecosystems to climate change. Annual Review of Ecology, Evolution, and Systematics 37: 373-404.

Hobday, A. J., Pecl, G. T. (2014). Identification of global marine hotspots: sentinels for change and vanguards for adaptation action. Reviews in Fish Biology and Fisheries 24: 415-425. DOI 10.1007/s11160-013-9326-6.

Hobday, A. J., Hartog, J., Spillman, C., Alves, O. (2011). Seasonal forecasting of tuna habitat for dynamic spatial management. Canadian Journal of Fisheries and Aquatic Sciences 68: $898-911$.

Hodgkinson, J. A., Hobday A. J., Pinkard, E. A. (2014). Climate adaptation in Australia's resource-extraction industries: ready or not? Regional Environmental Change 14(4): 1663-1678 DOI 10.1007/s10113-014-0618-8.

IPCC (2012). Managing the Risks of Extreme Events and Disasters to Advance Climate Change Adaptation. A Special Report of Working Groups I and II of the Intergovernmental Panel on Climate Change. Cambridge University Press, Cambridge, UK, and New York, NY, USA. 
IPCC (2013). Summary for Policymakers. In: Climate Change 2013: The Physical Science Basis. Contribution of Working Group I to the Fifth Assessment Report of the Intergovernmental Panel on Climate Change [Stocker, T. F., D. Qin, G.-K. Plattner, M. Tignor, S. K. Allen, J. Boschung, A. Nauels, Y. Xia, V. Bex and P. M. Midgley (eds.)]. Cambridge University Press, Cambridge, United Kingdom and New York, NY, USA Jentsch, A., Kreyling, J., Beierkuhnlein, C. (2007). A new generation of climate-change experiments: events, not trends. Frontiers in Ecology and Environment 5:365-374.

Lotze, H. K., Worm, B., Sommer, U. (2001): Strong bottom-up and top-down control of early life stages of macroalgae. Limnology and Oceanography 46: 749-757.

Marba, N., Duarte, C.M. (2010). Mediterranean warming triggers seagrass (Posidonia oceanica) shoot mortality. Global Change Biology 16: 2366-2375.

Marbà, N., Jorda, G., Agusti, S., Girard C., Duarte C. M. (2015). Footprints of climate change on Mediterranean Sea biota. Frontiers in Marine Science DOI=10.3389/fmars.2015.00056.

Mayer, M., Hoppe, P. (1987). Thermal comfort of man in different urban environments. Theoretical and Applied Climatology 38, 43-49.

Maynard J.A., Turner, P.J., Anthony, K.R.N., Baird, A.H., Berkelmans, R., Eakin, C.M., Johnson, J., Marshall, P.A., Packer, G.R., Rea, A., Willis, B.L. (2008). ReefTemp: An interactive monitoring system for coral bleaching using high-resolution SST and improved stress predictors. Geophysical Research Letters, 35, L05603.

Meehl, G.A., Tebaldi, C. (2004) More Intense, More Frequent, and Longer Lasting Heat Waves in the 21st Century. Science, 305: 994-997.

Mills, K.E., Pershing, A.J., Brown, C.J., Yong, C., Fu-Sung, C., Holland, D.S., Lehuta, S., Nye, J.A., Sun, J.C., Thomas, A.C., Wahle, R.A. (2013). Fisheries Management in a Changing Climate Lessons from the 2012 Ocean Heat Wave in the Northwest Atlantic. Oceanography 26: 191-195.

Palumbi, S. R., Barshis, D. J., Traylor-Knowles, N., Bay, R. A. (2014) Mechanisms of reef coral resistance to future climate change. Science 344: 895-898.

Parmesan, C. , Yohe, G. (2003). A globally coherent fingerprint of climate change impacts across natural systems. Nature, 421: 37-42.

Pearce, A., Lenanton, R., Jackson, G., Moore, J., Feng, M., Gaughan, D. (2011). The "marine heat wave" off Western Australia during the summer of 2010/11. Fisheries Research Report No. 222. Department of Fisheries, Western Australia. 40pp. 
Perkins, S.E. (2011). Biases and model agreement in the projections of climate extremes over the tropical Pacific. Earth Interactions, 15: 1-36. DOI: 10.1175/2011EI395.1

Perkins, S. E., Alexander, L. V. (2013). On the measurement of heat waves. Journal of Climate 26: 4500-4517. doi: http://dx.doi.org/10.1175/JCLI-D-12-00383.1

Perkins, S. E., Alexander, L. V., Nairn, J. (2012). Increasing frequency, intensity and duration of observed global heat waves and warm spells. Geophysical Research Letters, 39: 20, doi:10.1029/2012GL053361

Poloczanska, E. S., C. J. Brown, W. J. Sydeman, W. Kiessling, D. S. Schoeman, P. J. Moore, K. Brander, J. F. Bruno, L. B. Buckley, M. T. Burrows, C. M. Duarte, B. S. Halpern, J. Holding, C. V. Kappel, M. I. O'Connor, J. M. Pandolfi, C. Parmesan, F. Schwing, S. A. Thompson and A. J. Richardson (2013). Global imprint of climate change on marine life. Nature Climate Change: DOI: 10.1038/NCLIMATE1958.

Reynolds, R.W., Rayner, N.A., Smith, T.M., Stokes D.C., Wang W. (2002) An improved in situ and satellite SST analysis for climate. Journal of Climate, 15: 1609-1625.

Reynolds, R. W., Smith, T. M., Liu, C., Chelton, D. B., Casey, K. S., Schlax, M. G. (2007)

Daily High-Resolution-Blended Analyses for Sea Surface Temperature. Journal of Climate, 20: 5473-5496.

Richardson, A.J., Poloczanska, E.S. (2008). Under-resourced, under threat. Science, 320: 1294-1295.

Rosenzweig, C., Karoly, D., Vicarelli, M., Neofotis, P., Wu, Q., Casassa, G., Menzel, A., Root, T.L., Estrella, N., Seguin, B., Tryjanowski, P., Liu, C., Rawlins, S., Imeson, A. (2008). Attributing physical and biological impacts to anthropogenic climate change. Nature, 453: 353-357.

Russo, S., Dosio, A., Graversen, R. G., Sillmann, J., Carrao, H., Dunbar, M. B., Singleton, A., Montagna, P., Barbola, P., Vogt, J. V. (2014), Magnitude of extreme heat waves in present climate and their projection in a warming world. Journal of Geophysical Research Atmosphere, 119: 12,500-12,512, doi:10.1002/2014JD022098.

Santelices, B. (1990) Patterns of reproduction, dispersal and recruitment in seaweeds. Oceanography and Marine Biology Annual Review 28: 177-276.

Scannell, H.A., Pershing, A. J., Alexander, M. A., Thomas, A. C., Mills, K. E. (in review). Frequency of marine heatwaves in the North Atlantic and North Pacific since 1950.

Schoetter, R., Cattiaux J., Douville, H. (2014). Changes of western European heat wave characteristics projected by the CMIP5 ensemble. Climate Dynamics, DOI $10.1007 / \mathrm{s} 00382-014-2434-8$ 
Selig, E.R., Casey, K.S., Bruno, J.F. (2010). New insights into global patterns of ocean temperature anomalies: implications for coral reef health and management. Global Ecology and Biogeography 19: 397-411.

Sen Gupta, A., Brown, J. N., Jourdain, N. C., van Sebille, E., Ganachaud, A., Vergés A. (2015). Episodic and non-uniform shifts of thermal habitats in a warming ocean, Deep Sea Research Part II: Topical Studies in Oceanography, 113: 59-72, doi:10.1016/j.dsr2.2013.12.002.

Smale, D. A., Wernberg, T. (2009). Satellite-derived SST data as a proxy for water temperature in nearshore benthic ecology. Marine Ecology Progress Series 387:27-37

Smale, D. A., Wernberg, T. (2013). Extreme climatic event drives range contraction of a habitat-forming species. Proceedings of the Royal Society of London, Series B: Biological Sciences 280:20122829): http://dx.doi.org/10.1098/rspb.2012.2829.

Smith, M.D. (2011). The ecological role of climate extremes: current understanding and future prospects. Journal of Ecology 99: 651-655.

Sorte, C.J.B., Fuller, A., Bracken, M.E.S. (2010). Impacts of a simulated heat wave on composition of a marine community. Oikos 119: 1909-1918.

Spillman, C., Alves, O. (2009). Dynamical seasonal prediction of summer sea surface temperatures in the Great Barrier Reef. Coral Reefs 28: 197-206.

Spillman, C. (2011). Operational real-time seasonal forecasts for coral reef management. Journal of Operational Oceanography 4(1): 13-22.

Steadman, R. G. (1984). A universal scale of apparent temperature. Journal of Climate and Applied Meteorology, 23, 1674-1687

Tittensor, D. P., Mora, C., Jetz, W., Lotze, H. K., Ricard, D., Vanden Berghe, E., Worm, B. (2010). Global patterns and predictors of marine biodiversity across taxa. Nature 466: 1098-1101 doi:10.1038/nature09329.

Trenberth, K. (2012). Framing the way to relate climate extremes to climate change. $\underline{\text { Climatic }}$ Change 115:283-290.

Wernberg, T., Smale, D.A., Tuya, F., Thomsen, M.S., Langlois, T.J., de Bettignies, T., Bennett S., Rousseaux, C.S. (2013). An extreme climatic event alters marine ecosystem structure in a global biodiversity hotspot. Nature Climate Change, 3: 78-82.

Whitney, F.A. (2015), Anomalous winter winds decrease 2014 transition zone productivity in the NE Pacific, Geophysical Research Letters, 42: 428-431, doi:10.1002/2014GL062634 
764 Zhang, X., Hegerl, G., Zwiers, F.W., Kenyon, J. (2005). Avoiding inhomogeneity in percentile-based indices of temperature extremes. Journal of Climate 18(11): 16411651

Zhang, X., Alexander, L., Hegerl, G. C., Jones, P., Klein Tank, A., Peterson, T. C., Trewin, B., Zwiers, F. W. (2011). Indices for monitoring changes in extremes based on daily temperature and precipitation data. WIREs Climate Change doi:10.1002/wcc.147.

Zinke, J., Rountrey, A., Feng, M., Xie, S.-P., Dissard, D., Rankenburg, K., Lough, J. M., McCulloch, M. T. (2014). Corals record long-term Leeuwin current variability including Ningaloo Nino/Nina since 1795. Nature Communications 5:3607. 
Table 1: Examples of metrics commonly used to describe warming events in ecological studies.

\begin{tabular}{|c|c|c|}
\hline Metric & Description & Example \\
\hline $\begin{array}{l}\text { Maximum } \\
\text { Temperature }\left({ }^{\circ} \mathrm{C}\right)\end{array}$ & $\begin{array}{l}\text { Maximum temperature observed during a } \\
\text { heatwave event. E.g. } 30^{\circ} \mathrm{C} \text {. }\end{array}$ & Berkelmans et al. 2004 \\
\hline $\begin{array}{l}\text { Temperature } \\
\text { Anomaly }\left({ }^{\circ} \mathrm{C}\right)\end{array}$ & $\begin{array}{l}\text { Deviation from long-term mean (most often } \\
\text { monthly mean). E.g. } 3.5^{\circ} \mathrm{C} \text { above average. }\end{array}$ & $\begin{array}{l}\text { Sorte et al. 2010; } \\
\text { Wernberg et al. 2013; } \\
\text { Smale and Wernberg } 2013\end{array}$ \\
\hline $\begin{array}{l}\text { Thermal Stress } \\
\text { Anomaly (e.g. } \\
\text { weeks) }\end{array}$ & $\begin{array}{l}\text { Temperature deviation above a threshold value } \\
\text { (rather than the mean value), summed over some } \\
\text { period of time (e.g. weeks). E.g. TSA }=45^{\circ} \mathrm{C} \text { over } \\
10 \text { weeks. }\end{array}$ & Selig et al. 2010 \\
\hline $\begin{array}{l}\text { Degree Heating } \\
\text { Weeks }\left({ }^{\circ} \mathrm{C} \text {-weeks) }\right.\end{array}$ & $\begin{array}{l}\text { Degree Heating Weeks (DHW) reflect the } \\
\text { accumulation of heat stress by integrating SST } \\
\text { anomalies in excess of a threshold over a period } \\
\text { of weeks. In corals, thermal stress occurs when } \\
\text { sea surface temperatures exceed a certain } \\
\text { threshold (usually defined as } \sim 1^{\circ} \mathrm{C} \text { above the } \\
\text { maximum climatological mean), and so DHWs } \\
\text { are calculate as the sum of SST anomalies above } \\
\text { the } 1^{\circ} \mathrm{C} \text { threshold over a number of weeks (e.g. } 12 \\
\text { weeks). }\end{array}$ & $\begin{array}{l}\text { Eakin et al. } 2010 \\
\text { Donner } 2011\end{array}$ \\
\hline $\begin{array}{l}\text { Degree Heating } \\
\text { Days ( }{ }^{\circ} \mathrm{C} \text { days) }\end{array}$ & $\begin{array}{l}\text { The degree heating days (DHD) value is the } \\
\text { summed positive deviations of daily mean sea } \\
\text { surface temperatures }(\mathrm{x}(\mathrm{t})) \text { from the climatology } \\
\text { of long-term mean summer temperatures (LMST), } \\
\text { for a specified period (e.g. summer, December } 1^{\text {st }} \\
\text { to February } 28^{\text {th }} \text { in the Southern Hemisphere). } \\
\qquad D H D=\sum(x(t)-L M S T)\end{array}$ & Maynard et al. 2008 \\
\hline $\begin{array}{l}\text { Heating rate } \\
\left({ }^{\circ} \mathrm{C} / \text { day }\right)\end{array}$ & $\begin{array}{l}\text { Heating rate (HR) is defined as } \frac{D H D}{N D} \text { where DHD is } \\
\text { degree heating days as defined above, and ND is } \\
\text { the number of days in which daily mean sea } \\
\text { surface temperatures }(\mathrm{x}(\mathrm{t})) \text { have exceeded the } \\
\text { long-term mean summer temperatures. That is, } \\
\text { HR is the mean rate at which DHD have } \\
\text { accumulated throughout a period of time (e.g. } \\
\text { summer, December } 1^{\text {st }} \text { to February } 28^{\text {th }} \text { in the } \\
\text { Southern Hemisphere). }\end{array}$ & Maynard et al. 2008 \\
\hline
\end{tabular}


Table 2. Hierarchical classification of metrics to characterise marine heat waves (MHW). All definitions assume that daily SST data, T, and that a MHW has a discrete start day and end day. Note that we write $T$ both as a function of time $t, T(t)$, and as a function of year $y$ and day-of-year $d, T(y, d)$.

\begin{tabular}{|c|c|c|c|c|}
\hline & Name & Definition & & Units \\
\hline & Climatology & $\begin{array}{l}T_{\mathrm{m}}: \text { The } \\
\text { climatological } \\
\text { mean, calculated } \\
\text { over a reference } \\
\text { period, to which all } \\
\text { values are relative }\end{array}$ & 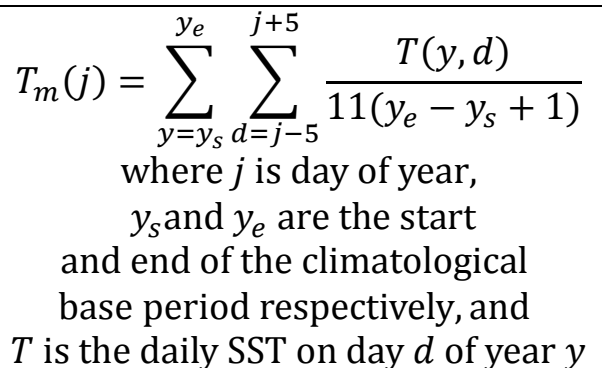 & ${ }^{\circ} \mathrm{C}$ \\
\hline & Threshold* & $\begin{array}{l}T_{\%}: \text { The seasonally } \\
\text { varying } \\
\text { temperature value } \\
\text { that defines a } \\
\text { MHW (e.g. } T_{90} \text { is } \\
\text { the } 90^{\text {th }} \text { percentile } \\
\text { value based on the } \\
\text { baseline periods) }\end{array}$ & $\begin{array}{l}\qquad T_{90}(j)=P_{90}(X) \\
\text { where } P_{90} \text { is the } 90^{t h} \text { percentile } \\
\text { and } P_{90}(X) \text { where } X=\left\{T(y, d) \mid y_{\mathrm{s}}<=\right. \\
\left.y<=y_{\mathrm{e}}, j-5<=d<=j+5\right\}\end{array}$ & ${ }^{\circ} \mathrm{C}$ \\
\hline & $\begin{array}{l}\text { Start and end } \\
\text { of MHW }\end{array}$ & $\begin{array}{l}t_{\mathrm{e}}, t_{\mathrm{s}}: \text { dates on } \\
\text { which a MHW } \\
\text { begins and ends. }\end{array}$ & $\begin{array}{c}t_{s} \text { is the time, } t \text {, where } \\
T(t)>T_{90}(j) \\
\text { and } T(t-1)<T_{90}(j) \\
t_{e} \text { is the time, } t \text {, where } \\
t_{e}>t_{s} \text { and } \\
T(t)<T_{90}(j) \\
\text { and } T(t-1)>T_{90}(j) \\
\text { For MHWs, } t_{e}-t_{s} \geq 5 \text {, and where } \\
\text { gap } \leq 2 \text { days (see text) }\end{array}$ & days \\
\hline \multirow[t]{2}{*}{ Primary } & Duration & $\begin{array}{l}D \text { : Consecutive } \\
\text { period of time that } \\
\text { temperature } \\
\text { exceeds the } \\
\text { threshold }\end{array}$ & $D=t_{e}-t_{s}$ & days \\
\hline & $\begin{array}{l}\text { Intensity } \\
\text { (max/mean/var } \\
\text { iance) }\end{array}$ & $\begin{array}{l}\mathrm{i}_{\text {max }}: \text { highest } \\
\text { temperature } \\
\text { anomaly value } \\
\text { during the MHW } \\
\mathrm{i}_{\text {mean }}: \text { mean } \\
\text { temperature } \\
\text { anomaly during the } \\
\text { MHW } \\
\mathrm{i}_{\text {var: }}: \text { variation in } \\
\text { intensity of the } \\
\text { MHW over the } \\
\text { duration }\end{array}$ & $\begin{array}{c}i_{\text {max }}=\max \left(T(t)-T_{m}(j)\right) \\
i_{\text {mean }}=\overline{T(t)-T_{m}(J)} \\
i_{v a r}=\sigma_{T(t)} \\
\text { where } t_{s} \leq t \leq t_{e} \\
j\left(t_{s}\right) \leq j \leq j\left(t_{e}\right) \\
\sigma \text { is the standard deviation, and } \\
\text { the overbar indicates the time mean. }\end{array}$ & ${ }^{\circ} \mathrm{C}$ \\
\hline Secondary & Rate measures & $\begin{array}{l}\mathrm{r}_{\text {onset }}: \text { time from the } \\
\text { onset of the MHW } \\
\text { to the maximum } \\
\text { intensity. } \\
\mathrm{r}_{\text {decline }} \text { time from }\end{array}$ & $r_{\text {onset }}=\frac{i_{\max }-\left(T\left(t_{s}-1\right)-T_{m}(j-1)\right)}{t_{\max }-\left(t_{s}-1\right)}$ & ${ }^{\circ} \mathrm{C} /$ day \\
\hline
\end{tabular}




\begin{tabular}{|c|c|c|c|c|}
\hline & & $\begin{array}{l}\text { the maximum } \\
\text { intensity to the end } \\
\text { of the MHW. }\end{array}$ & $\begin{array}{c}r_{\text {decline }}=\frac{i_{\max }-\left(T\left(t_{e}\right)-T_{m}(j)\right)}{t_{e}-t_{\max }} \\
\text { where } t_{\max } \text { is the time of } M H W_{\text {imax }}\end{array}$ & \\
\hline & $\begin{array}{l}\text { Cumulative } \\
\text { measure }\end{array}$ & $\begin{array}{l}\mathrm{i}_{\text {cum }} \text { sum of daily } \\
\text { intensity anomalies. } \\
\text { Note that the integral omits } \\
\text { which his below the } \\
\text { threshold. }\end{array}$ & $i_{\text {cum }}=\int_{t_{s}}^{t_{e-1}}\left(T(t)-T_{m}(j)\right) d t$ & ${ }^{\circ} \mathrm{C}$ days \\
\hline & Spatial extent & $\begin{array}{l}\text { A: Area of ocean } \\
\text { meeting the MHW } \\
\text { definition } \\
\text { L: Length of } \\
\text { coastline for the } \\
\text { MHW }\end{array}$ & $\begin{array}{l}\mathrm{A}=\text { area over which MHW detected } \\
\mathrm{L}=\text { length of coast where MHW } \\
\text { detected }\end{array}$ & $\begin{array}{l}\mathrm{km}^{2} \\
\mathrm{~km}\end{array}$ \\
\hline Tertiary & $\begin{array}{l}\text { Preconditioning } \\
\text { factors }\end{array}$ & $\begin{array}{l}\text { Factors such as time } \\
\text { of year relative to the } \\
\text { onset of the MHW, or } \\
\text { periods of above } \\
\text { mean temperature } \\
\text { preceding the MHW } \\
\text { may lead to greater } \\
\text { impacts. }\end{array}$ & $\mathrm{n} / \mathrm{a}$ & $\begin{array}{l}\text { Various } \\
- \\
\text { specific } \\
\text { to study } \\
\text { system }\end{array}$ \\
\hline
\end{tabular}


Table 3. Qualitative comparison of different temperature data sources and their suitability to provide primary, secondary and tertiary marine heat wave metrics for sea surface temperature (SST). Relative scores for each option are in the range 1 to 4 , where 1 indicates that only low resolution metrics can be derived and 4 indicates that high resolution metrics can be derived (N/A indicates no utility). The quantities maximum MHW intensity $\left(i_{\max }\right)$ and cumulative effect $\left(i_{\text {cum }}\right)$ are defined in Figure 1 and Table 2. Preconditioning is defined as the conditions that facilitate the onset of the MHW. Continuous data generally allow an understanding of environmental conditions leading up to the event.

\begin{tabular}{|c|c|c|c|c|c|c|c|c|c|c|}
\hline \multirow[b]{3}{*}{ Data source } & \multicolumn{6}{|c|}{ Metrics } & \multirow{2}{*}{\multicolumn{4}{|c|}{ Other considerations }} \\
\hline & \multicolumn{3}{|c|}{ Primary } & \multicolumn{2}{|c|}{ Secondary } & \multirow{2}{*}{$\begin{array}{l}\text { Tertiary } \\
\begin{array}{l}\text { Precondition } \\
\text { ing }\end{array}\end{array}$} & & & & \\
\hline & $\begin{array}{l}\text { Duration } \\
\text { (D) } \\
\text { [days] }\end{array}$ & $\begin{array}{l}\mathrm{i}_{\max } \\
{\left[{ }^{\circ} \mathrm{C}\right]}\end{array}$ & $\begin{array}{l}\mathrm{i}_{\text {mean }}, \\
\mathrm{i}_{\text {cum }} \\
{\left[{ }^{\circ} \mathrm{C}\right.} \\
\text { days }]\end{array}$ & $\begin{array}{c}\text { Rate of } \\
\text { event } \\
\text { onset/decay } \\
{\left[{ }^{\circ} \mathrm{C} / \text { day }\right]} \\
\end{array}$ & $\begin{array}{c}\text { Spatial } \\
\text { area }(\mathrm{A}) \\
{\left[\mathrm{km}^{2}\right]}\end{array}$ & & $\begin{array}{l}\text { Length of } \\
\text { records }\end{array}$ & $\begin{array}{l}\text { Temporal } \\
\text { resolution }\end{array}$ & $\begin{array}{l}\text { Quality } \\
\text { control }\end{array}$ & $\begin{array}{c}\text { Data } \\
\text { consistency }\end{array}$ \\
\hline $\begin{array}{l}\text { In situ temperatures (e.g. } \\
\text { loggers) }\end{array}$ & 4 & 4 & 4 & 4 & $\begin{array}{c}1 \text { (if } \\
\text { multiple } \\
\text { loggers), } \\
\text { else N/A }\end{array}$ & 2 & High & High & Low & $\begin{array}{l}\text { Low/ } \\
\text { Med }\end{array}$ \\
\hline Satellite SST & 3 & 3 & 3 & 4 & 3 & 3 & Med & High & High & Low/Med \\
\hline $\begin{array}{l}\text { Argo floats (NB: gridded } \\
\text { products do not provide } \\
\text { SST) }\end{array}$ & N/A & N/A & 1 & 1 & 2 & 2 & Low & Low & High & Med/High \\
\hline $\begin{array}{l}\text { Reconstructed monthly } \\
\text { data (e.g. ERSST, } \\
\text { HadISST) } \\
\end{array}$ & 2 & 2 & N/A & 2 & 2 & 2 & High & Low & High & Med \\
\hline $\begin{array}{l}\text { Palaeo-proxy SST } \\
\text { (seasonal to annual } \\
\text { records, e.g. coral cores) }\end{array}$ & N/A & N/A & N/A & N/A & N/A & N/A & High & Low & Low & Low/Med \\
\hline $\begin{array}{l}\text { Global Climate Models } \\
\text { (e.g. daily SST fields) }\end{array}$ & 2 & 2 & 2 & 3 & 2 & 2 & High & Low & N/A & High \\
\hline $\begin{array}{l}\text { Re-analysis SST products } \\
\text { (e.g. BRAN) }\end{array}$ & 3 & 3 & 3 & 3 & 3 & 3 & Med & High & $\begin{array}{l}\text { Low/ } \\
\text { Med }\end{array}$ & Med/High \\
\hline $\begin{array}{l}\text { Regional Ocean Models } \\
\text { (e.g. OFAM) }\end{array}$ & 3 & 3 & 3 & 3 & 2 & 2 & Low & High & N/A & High \\
\hline $\begin{array}{l}\text { Traditional Ecological } \\
\text { Knowledge, citizen } \\
\text { science, and anecdotal } \\
\text { information }\end{array}$ & N/A & 1 & N/A & N/A & N/A & 1 & Med/High & Low & Low & Low \\
\hline
\end{tabular}




\section{Figure Legends}

Figure 1. Schematic of metrics used to define a marine heatwave (MHW). (a) Threshold values for each location for each day of the year are defined based on the $90^{\text {th }}$ percentile value. (b) These percentile values vary through the year (dashed line), as does the climatological mean (solid line). (c) Short duration heat spikes less than five days are not MHWs. A temperature event that is at least five days or longer than this minimum duration is defined according to duration $\left(\mathrm{MHW}_{\mathrm{D}}\right)$ above the threshold value, intensity ( $\mathrm{i}_{\max }$, temperature above the climatological mean) and the rate of temperature increase $\left(\mathrm{r}_{\mathrm{onset}}\right)$ and decrease $\left(r_{\text {decline }}\right)$ during the event. The mean event intensity (open circle, $\left.i_{\text {mean }}\right)$ is the mean intensity during the MHW, while $\mathrm{i}_{\text {cum }}$ (shading) is the sum of daily intensities during the MHW. The start and end days of the MHW are represented by $t_{s}$ and $t_{e}$ respectively.

Figure 2. Taxonomy of heat waves as distinguished by the metrics duration (D), maximum intensity $\left(i_{\max }\right)$, cumulative intensity $\left(i_{\text {cum }}\right)$, and rate of onset $\left(r_{\text {onset }}\right)$. A marine heat wave (MHW) with regular warming onset and decline (panel a) can be distinguished from one with similar duration and maximum intensity but asymmetric warming (panel b) by the cumulative intensity metric ( $\left.\mathrm{i}_{\text {cum }}\right)$. This asymmetric MHW (b) is distinguished from one with a slow onset and rapid decline (panel c) by the rate of warming $\left(\mathrm{r}_{\text {onset }}\right)$ metric. A lower intensity MHW (panel d) is distinguished by its maximum intensity ( $i_{\max }$ ), while a short MHW (panel e) is distinguished by its duration $(D)$. The dashed line indicates the threshold value. Arrows 813 between the plots indicate the major change $(\Delta)$ between the plots. Index values are indicative 814 only in this schematic.

Figure 3. First row: Sea surface temperatures (SST) anomaly on the peak day of three marine heatwaves (MHW) discussed in the text. (a) Western Australia 2011, (b) northern Mediterranean 2003, (c) northwest Atlantic 2012. Dots show the locations from which $1 / 4$ resolution time series of SST were extracted from NOAA OI SST for the detection of MHWs in each case study region. Second row: The SST climatology (blue), $90^{\text {th }}$ percentile MHW threshold (green), and SST time series (black) for each MHW at each location. The red filled area indicates the period of time associated with the identified MHW, while shaded orange indicates other MHWs identified over the year. Third row: The duration (D) of each MHW detected in the time series from each location, with every tenth event identified on the upper 
$825 \mathrm{x}$-axis. Fourth row: As for the third row, but illustrating maximum intensity $\left(\mathrm{i}_{\max }\right)$ of each 826 MHW event in each location. Fifth row: As for the third row, but illustrating cumulative 827 intensity ( $i_{\text {cum }}$ ) of each MHW event from each location. The WA and northwest Atlantic 828 MHWs are the largest by maximum intensity, such that the red and yellow bars are the same. 829 The northwest Atlantic event is not the largest according to duration or cumulative intensity, 830 but the red bar obscures the yellow bar since they are so close in time. 
(a)

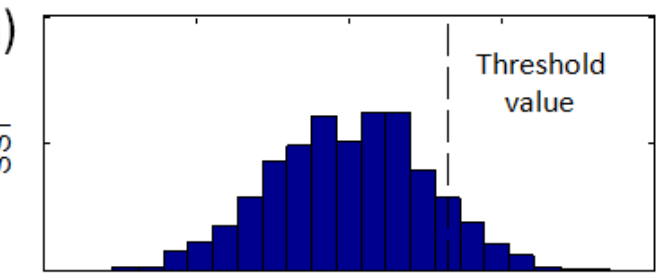

Frequency

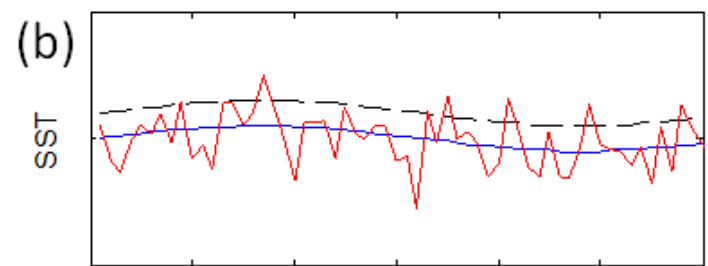

Day of Year

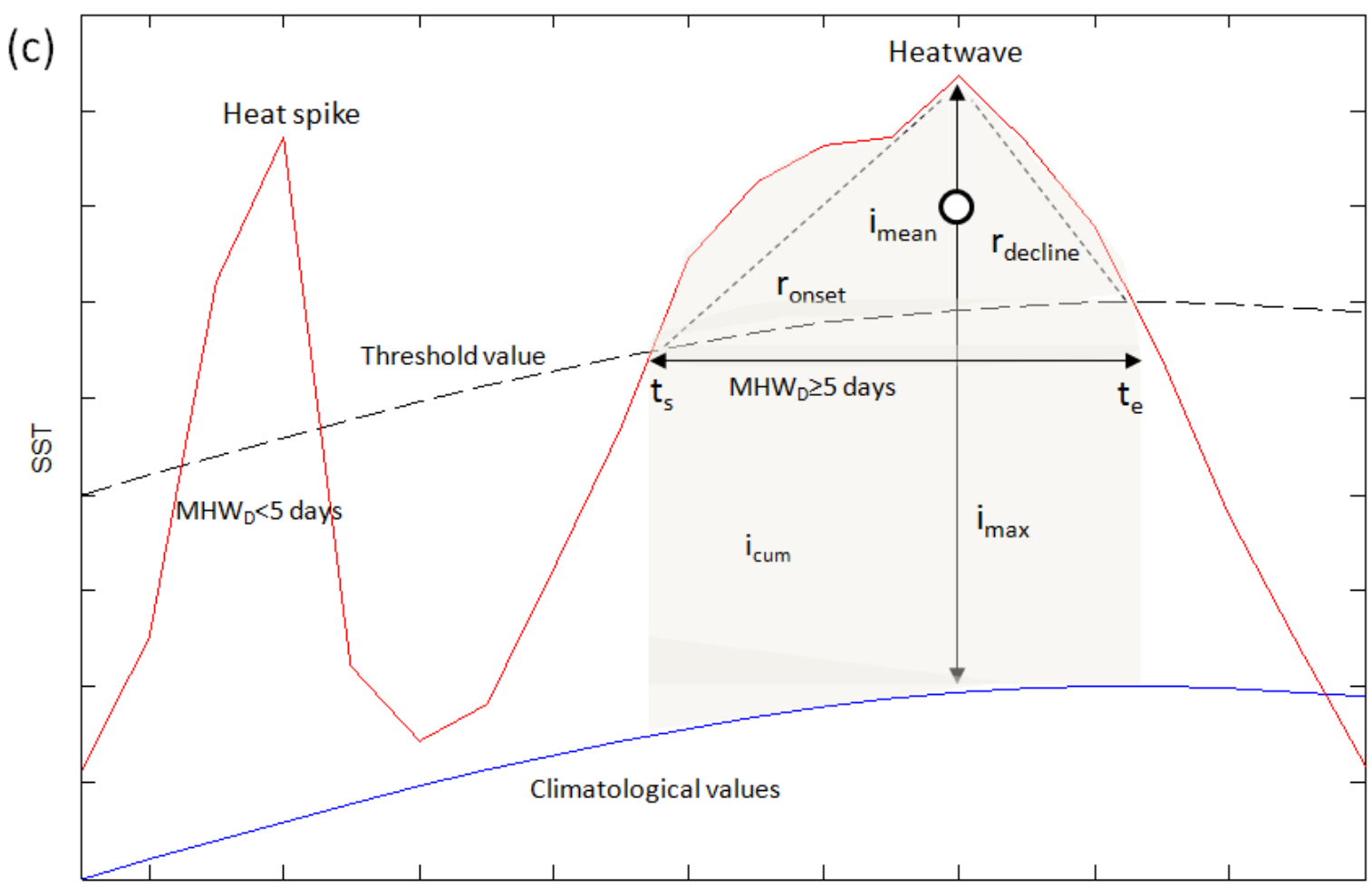

Day of Year

Figure 1. Schematic of metrics used to define a marine heatwave (MHW). (a) Threshold values for each location for each day of the year are defined based on the $90^{\text {th }}$ percentile value. (b) These percentile values vary through the year (dashed line), as does the climatological mean (solid line). (c) Short duration heat spikes less than five days are not MHWs. A temperature event that is at least five days or longer than this minimum duration is defined according to duration $\left(\mathrm{MHW}_{\mathrm{D}}\right)$ above the threshold value, intensity ( $\mathrm{i}_{\max }$, temperature above the climatological mean) and the rate of temperature increase $\left(\mathrm{r}_{\text {onset }}\right)$ and decrease $\left(r_{\text {decline}}\right)$ during the event. The mean event intensity (open circle, $\left.i_{\text {mean }}\right)$ is the mean intensity during the MHW, while $\mathrm{i}_{\text {cum }}$ (shading) is the sum of daily intensities during the MHW. The start and end days of the MHW are represented by $t_{\mathrm{s}}$ and $t_{\mathrm{e}}$ respectively. 


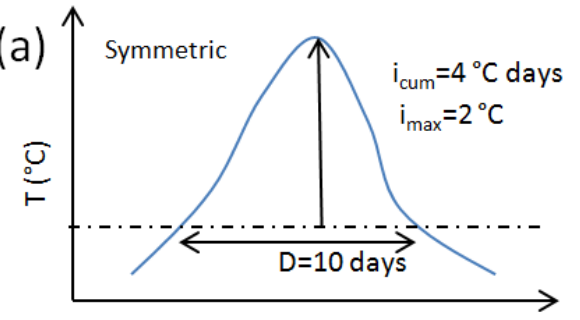

(b)
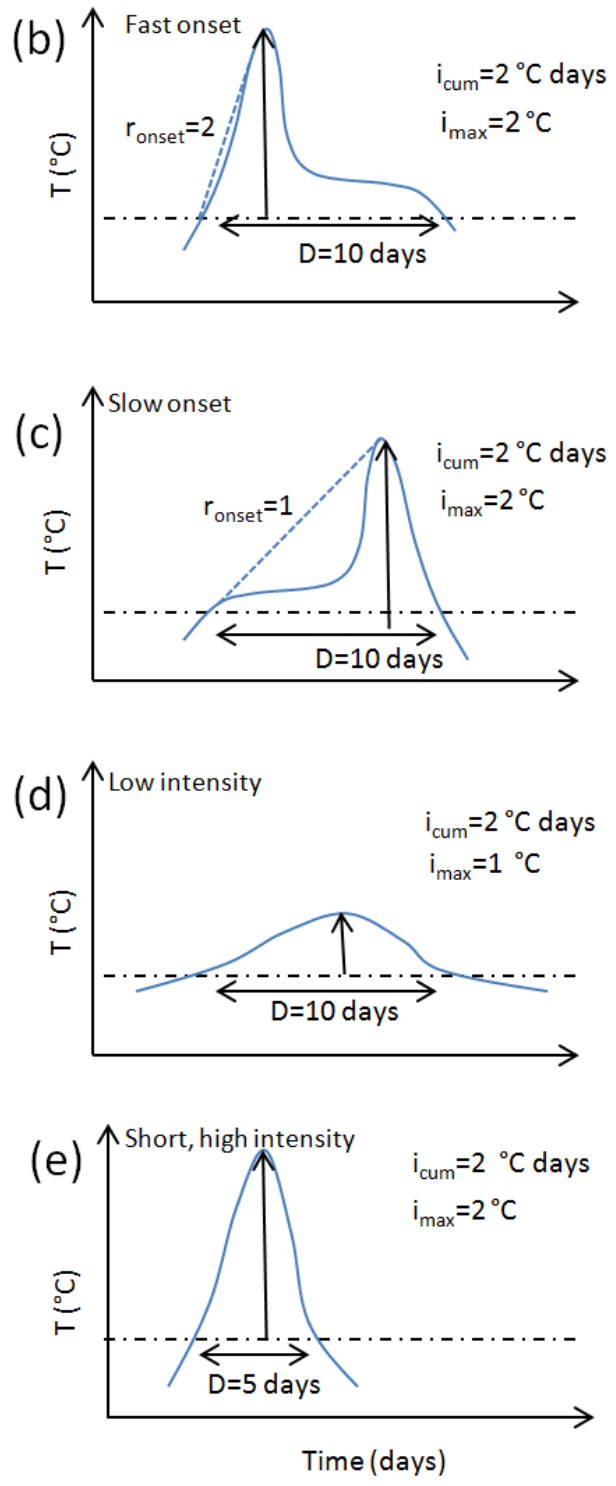

Figure 2. Taxonomy of heat waves as distinguished by the metrics duration (D), maximum intensity $\left(i_{\max }\right)$, cumulative intensity $\left(i_{\text {cum }}\right)$, and rate of onset $\left(\mathrm{r}_{\text {onset }}\right)$. A marine heat wave (MHW) with regular warming onset and decline (panel a) can be distinguished from one with similar duration and maximum intensity but asymmetric warming (panel b) by the cumulative intensity metric ( $\left.i_{\text {cum }}\right)$. This asymmetric MHW (b) is distinguished from one with a slow onset and rapid decline (panel c) by the rate of warming $\left(\mathrm{r}_{\text {onset }}\right)$ metric. A lower intensity MHW (panel d) is distinguished by its maximum intensity $\left(i_{\max }\right)$, while a short MHW (panel e) is distinguished by its duration $(D)$. The dashed line indicates the threshold value. Index values are indicative only in this schematic. 
(a)
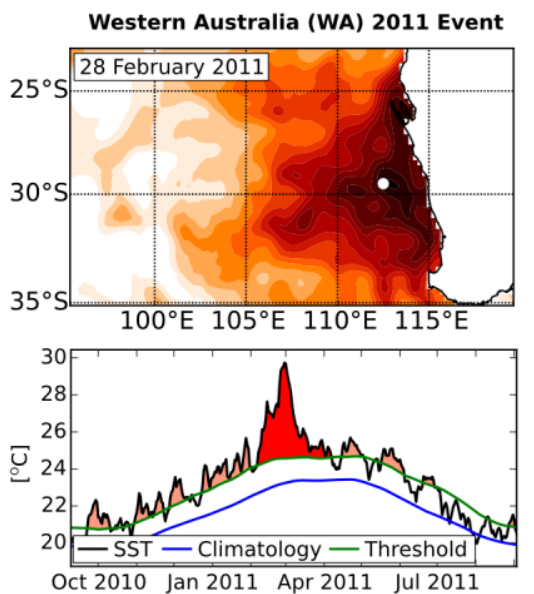

MHW event number

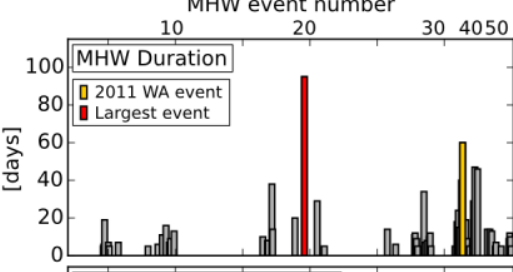

6 MHW Maximum Intensity
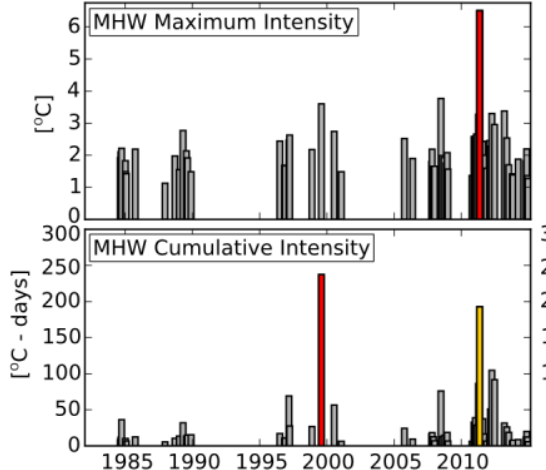

(b)
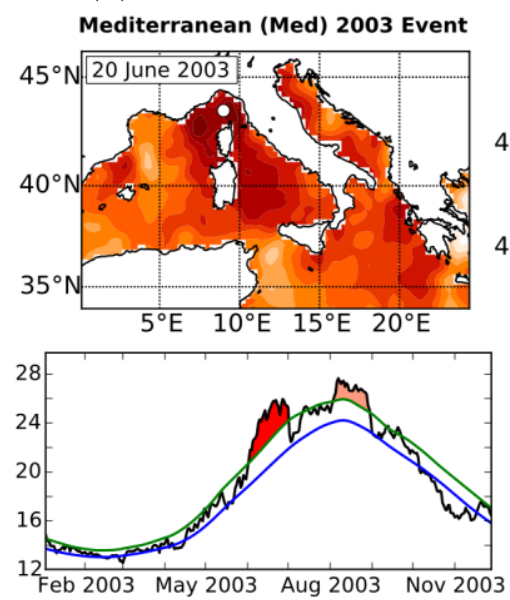

MHW event number
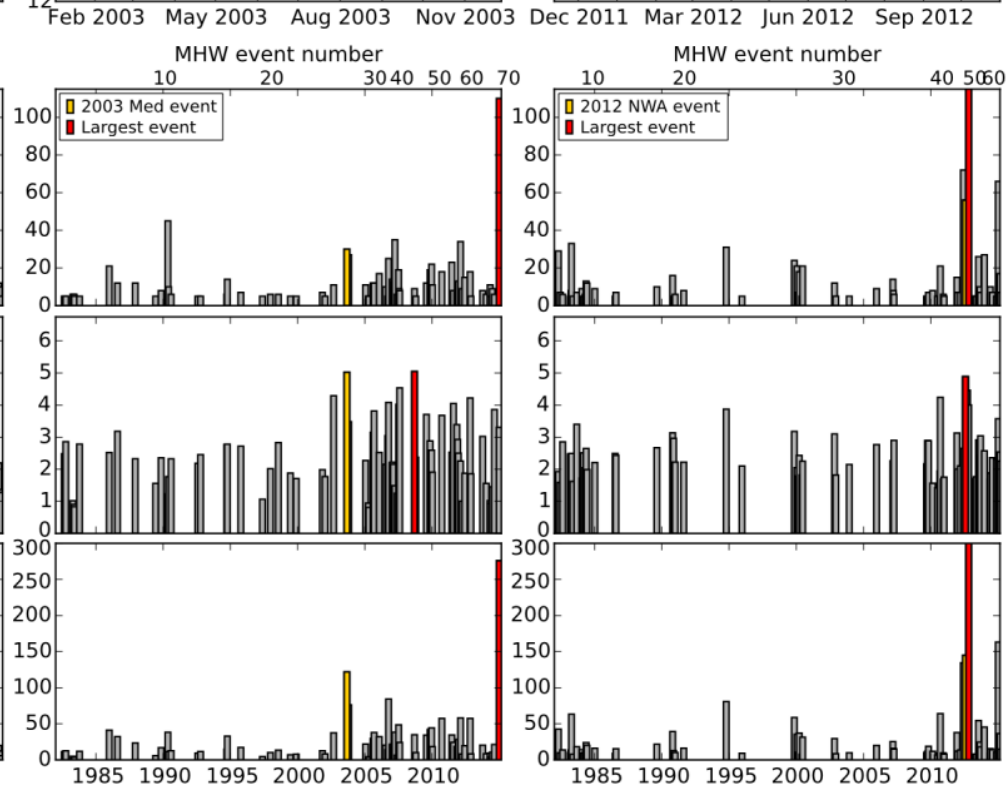

(c)
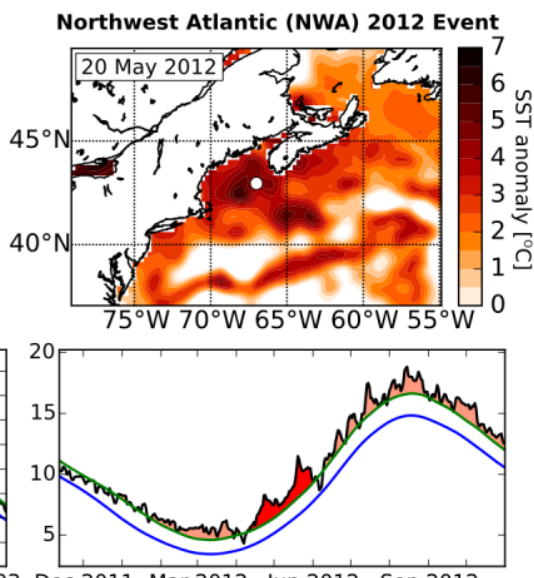


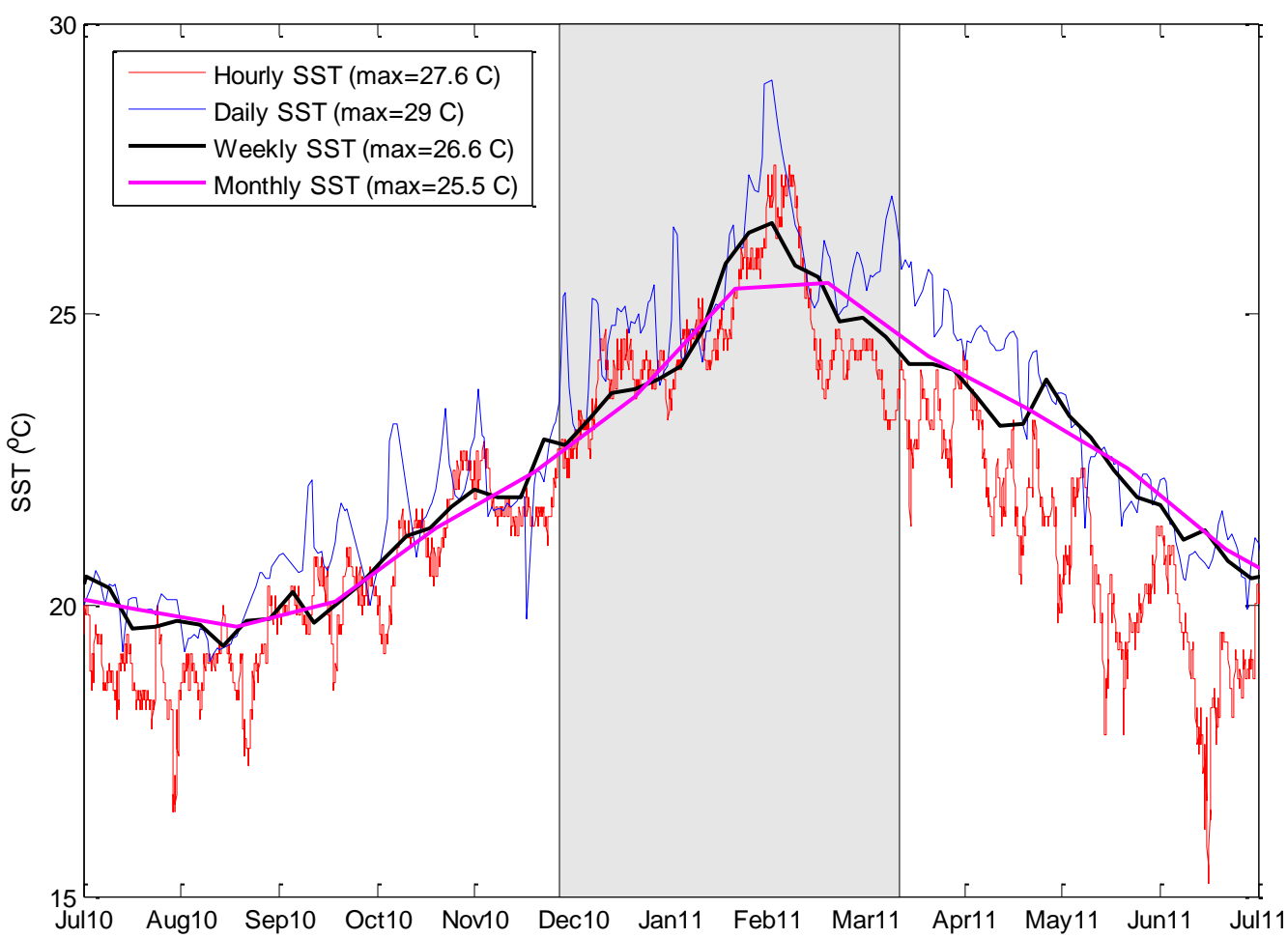

893 Figure 4. Temperature time series during the twelve months bounding the 2011 'Ningaloo

Niño' marine heat wave (shaded area: December 2011 to April 2012) as measured by four different data sources; weekly and monthly Reynolds SST $\left(29.5-30.5^{\circ} \mathrm{S} ; 114.5-115.5^{\circ} \mathrm{E}\right)$, daily satellite $\operatorname{SST}\left(29.5-30.5^{\circ} \mathrm{S} ; 114.5-115.5^{\circ} \mathrm{E}\right)$, and an hourly in situ logger from Jurien Bay $\left(3018.5^{\circ} \mathrm{S} 11458.3^{\circ} \mathrm{E}\right)$. 